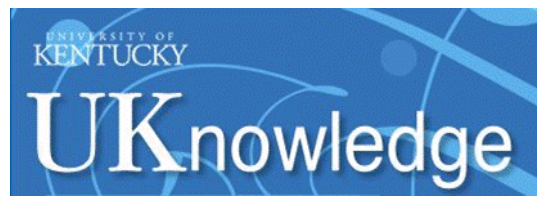

University of Kentucky

UKnowledge

\title{
A 6-CpG Validated Methylation Risk Score Model for Metabolic Syndrome: The HyperGEN and GOLDN Studies
}

\author{
Bertha A. Hidalgo \\ University of Alabama at Birmingham \\ Bre Minniefield \\ University of Alabama at Birmingham \\ Amit Patki \\ University of Alabama at Birmingham \\ Rikki Tanner \\ University of Alabama at Birmingham \\ Minoo Bagheri \\ Vanderbilt University
}

See next page for additional authors

Follow this and additional works at: https://uknowledge.uky.edu/epidemiology_facpub

Part of the Biostatistics Commons, and the Epidemiology Commons

Right click to open a feedback form in a new tab to let us know how this document benefits you.

\section{Repository Citation}

Hidalgo, Bertha A.; Minniefield, Bre; Patki, Amit; Tanner, Rikki; Bagheri, Minoo; Tiwari, Hemant K.; Arnett, Donna K.; and Irvin, Marguerite Ryan, "A 6-CpG Validated Methylation Risk Score Model for Metabolic Syndrome: The HyperGEN and GOLDN Studies" (2021). Epidemiology and Environmental Health Faculty Publications. 86.

https://uknowledge.uky.edu/epidemiology_facpub/86

This Article is brought to you for free and open access by the Epidemiology and Environmental Health at UKnowledge. It has been accepted for inclusion in Epidemiology and Environmental Health Faculty Publications by an authorized administrator of UKnowledge. For more information, please contact UKnowledge@lsv.uky.edu. 


\title{
A 6-Cpg Validated Methylation Risk Score Model for Metabolic Syndrome: The HyperGEN and GOLDN Studies
}

\author{
Digital Object Identifier (DOI) \\ https://doi.org/10.1371/journal.pone.0259836 \\ Notes/Citation Information \\ Published in PLOS ONE, v. 16, issue 11, e0259836. \\ (c) 2021 Hidalgo et al.
}

This is an open access article distributed under the terms of the Creative Commons Attribution License, which permits unrestricted use, distribution, and reproduction in any medium, provided the original author and source are credited.

\section{Authors}

Bertha A. Hidalgo, Bre Minniefield, Amit Patki, Rikki Tanner, Minoo Bagheri, Hemant K. Tiwari, Donna K. Arnett, and Marguerite Ryan Irvin 


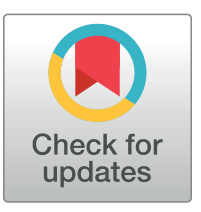

\section{G OPEn ACCESS}

Citation: Hidalgo BA, Minniefield B, Patki A, Tanner R, Bagheri M, Tiwari HK, et al. (2021) A 6-CpG validated methylation risk score model for metabolic syndrome: The HyperGEN and GOLDN studies. PLoS ONE 16(11): e0259836. https://doi. org/10.1371/journal.pone.0259836

Editor: Kyle J. Burghardt, Wayne State University, UNITED STATES

Received: April 19, 2021

Accepted: October 27, 2021

Published: November 15, 2021

Peer Review History: PLOS recognizes the benefits of transparency in the peer review process; therefore, we enable the publication of all of the content of peer review and author responses alongside final, published articles. The editorial history of this article is available here: https://doi.org/10.1371/journal.pone.0259836

Copyright: ๑ 2021 Hidalgo et al. This is an open access article distributed under the terms of the Creative Commons Attribution License, which permits unrestricted use, distribution, and reproduction in any medium, provided the original author and source are credited.

Data Availability Statement: All data is available on dbgap and/or prior publications in the literature. https://www.ncbi.nlm.nih.gov/projects/gap/cgi-bin/
RESEARCH ARTICLE

\section{A 6-CpG validated methylation risk score model for metabolic syndrome: The HyperGEN and GOLDN studies}

\author{
Bertha A. Hidalgo ${ }^{1 *}$, Bre Minniefield ${ }^{1}$, Amit Patki ${ }^{2}$, Rikki Tanner ${ }^{1}$, Minoo Bagheri ${ }^{3}$, \\ Hemant K. Tiwari ${ }^{2}$, Donna K. Arnett ${ }^{4}$, Marguerite Ryan Irvin ${ }^{1}$ \\ 1 Department of Epidemiology, Ryals School of Public Health, University of Alabama at Birmingham, \\ Birmingham, AL, United States of America, 2 Department of Biostatistics, Ryals School of Public Health, \\ University of Alabama at Birmingham, Birmingham, AL, United States of America, 3 Center for Precision \\ Medicine, Vanderbilt University Medical Center, Nashville, TN, United States of America, 4 College of Public \\ Health, University of Kentucky, Lexington, KY, United States of America \\ * bhidalgo@uab.edu
}

\section{Abstract}

There has been great interest in genetic risk prediction using risk scores in recent years, however, the utility of scores developed in European populations and later applied to nonEuropean populations has not been successful. The goal of this study was to create a methylation risk score (MRS) for metabolic syndrome (MetS), demonstrating the utility of MRS across race groups using cross-sectional data from the Hypertension Genetic Epidemiology Network (HyperGEN, N = 614 African Americans (AA)) and the Genetics of Lipid Lowering Drugs and Diet Network (GOLDN, N = 995 European Americans (EA)). To demonstrate this, we first selected cytosine-guanine dinucleotides (CpG) sites measured on Illumina Methyl450 arrays previously reported to be significantly associated with MetS and/or component conditions in more than one race/ethnic group (CPT1A cg00574958, PHOSPHO1 cg02650017, ABCG1 cg06500161, SREBF1 cg11024682, SOCS3 cg18181703, TXNIP cg19693031). Second, we calculated the parameter estimates for the $6 \mathrm{CpGs}$ in the HyperGEN data (AA) and used the beta estimates as weights to construct a MRS in HyperGEN (AA), which was validated in GOLDN (EA). We performed association analyses using logistic mixed models to test the association between the MRS and MetS, adjusting for covariates. Results showed the MRS was significantly associated with MetS in both populations. In summary, a MRS for MetS was a strong predictor for the condition across two race groups, suggesting MRS may be useful to examine metabolic disease risk or related complications across race/ethnic groups.

\section{Introduction}

Genome wide association studies (GWAS) have examined the cumulative effect of novel, single variants on both quantitative trait variance and disease status, by summing up independent risk alleles at each locus weighted by effect size, otherwise known as a genetic risk score (GRS) 
study.cgi?study_id=phs001293.v2.p1 https://www. omicsdi.org/dataset/dbgap/phs000741.

Funding: The authors received no specific funding for this work.

Competing interests: The authors have declared that no competing interests exist.
[1]. While once limited by small sample sizes, GRSs have since benefitted from the growth and development of large-disease based consortia, along with improved methodology which allow for the aggregation of thousands to millions of genetic variants (i.e. polygenic risk scores, PRS), which better inform risk prediction [2]. A major limitation of GRS-including PRS-is that they have been developed and optimized for European-ancestry populations, thus limiting their utility and generalizability in non-European ancestry populations [3, 4]. Overall, GWAS results and GRS have been difficult to replicate across race groups for complex disease. This is in contrast to data on DNA methylation which has demonstrated more successful cross-race replication $[3,5,6]$. Given these observations we aimed to apply statistical approaches common to GRS and PRS to epigenome-wide association (EWAS) data to evaluate if methylation risk score (MRS) may further enhance accuracy for prediction of metabolic syndrome, a cluster of conditions that can increase risk for cardiometabolic diseases. We hypothesized that leveraging existing EWAS data and previously reported associations between cytosine-phosphate-guanine $(\mathrm{CpG})$ sites and metabolic syndrome may help identify persons with elevated risk for MetS.

There is a rich body of literature demonstrating independent associations between DNA methylation loci and MetS and/or conditions related to MetS such as obesity [7-9], insulin resistance (9), and type 2 diabetes [10-12]. In this study, we leverage previously reported CpGs that have been significantly associated with MetS and/or conditions comprising MetS in more than one race/ethnic group: waist circumference [5], triglycerides [13], fasting blood glucose [11], systolic and diastolic blood pressure [14], and HDL cholesterol [15, 16], to construct the MRS. Independent CpGs included were cg00574958 from carnitine palmitoyl transferase 1A (CPT1A), cg02650017 from Phosphoethanolamine/Phosphocholine Phosphatase 1 (PHOSPHO1), cg06500161 from ATP Binding Cassette Subfamily G Member 1 (ABCG1), cg11024682 from Sterol Regulatory Element Binding Transcription Factor 1 (SREBF1), cg18181703 from Suppressor Of Cytokine Signaling 3 (SOCS3), and cg19693031 from Thioredoxin Interacting Protein (TXNIP). Bolstering to the validity of our CpG selection each gene has strong biological plausibility for association with MetS including roles in fatty acid metabolism (CPT1A) [17], lipid homeostasis and metabolism (SREBF1 [18], ABCG1) [19], skeletal endocrine regulation of metabolism (PHOSPHO1) [20], cytokine signaling (SOCS3) [21] and oxidative stress (TXNIP) [22].

Like existing GWAS data existing methylation data can be used to calculate risk scores that could become useful for diagnosis and/or prevention. Building on GRS methods we used a weighted sum approach to create a MRS among African Americans from the Hypertension Genetic Epidemiology Network (HyperGEN), Wevalidated the score in European Americans from Genetics of Lipid Lowering Drugs and Diet Network (GOLDN). We further examined the score's association with the individual MetS components and stratified by sex.

\section{Methods}

\section{Discovery and validation study populations}

Data for the discovery phase of this study was obtained from the HyperGEN study. HyperGEN is a cross-sectional study including over 1900 African-Americans from families, which included at least two siblings with hypertension onset before age 60 [23]. The study purpose was to examine possible interactions between genetic and non-genetic determinants of hypertension. In 2015, an ancillary epigenetic study was conducted on stored HyperGEN samples in the upper and lower tertial of echocardiography measured left ventricular mass [24]. After excluding those missing relevant phenotype data as previously described [25] a total 614 participants were included in the analysis. Participants in the HyperGEN and GOLDN studies 
provided written and oral informed consent to participate in these studies and both studies were approved by the Institutional Review Board at the University of Alabama at Birmingham.

Validation was conducted in GOLDN study [26]. European ancestry families in GOLDN were recruited from the Family Heart Study at two centers, Minneapolis, MN and Salt Lake City, UT to participate in a diet and/or drug intervention. In each case, only families with at least two siblings were recruited and only participants who did not take lipid-lowering agents (pharmaceuticals or nutraceuticals) for at least 4 weeks prior to the initial visit were included. For the present study, $994 \mathrm{GOLDN}$ participants had available methylation data for a validation study of the HyperGEN MRS. Sample characteristics as well as clinical and lifestyle factors were considered in HyperGEN and GOLDN, including blood pressure, antihypertensive and lipid lowering medications, fasting blood glucose, triglycerides, HDL cholesterol, height, weight, and waist circumference have been described [7-9]. We used the published joint harmonized criteria to define MetS in HyperGEN in both studies [27].

\section{DNA methylation and data processing}

HyperGEN. The Illumina HumanMethylation450 array was used to analyze DNA extracted from buffy coat obtained from whole blood samples at $>480,000$ cytosine-phosphate-guanine (CpG) sites. Briefly, 500 ng of buffy coat DNA was hybridized to the Methyl450 array after bisulfite conversion with EZ DNA kits (Zymo Research, Irvine, CA) prior to standard Illumina amplification, hybridization, and imaging steps. The resulting intensity files were analyzed with Illumina's GenomeStudio, which generated beta $(\beta)$ scores (i.e., the proportion of total signal from the methylation-specific probe or color channel) and "detection $p$ values" (probability that the total intensity for a given probe falls within the background signal intensity). Quality control (QC) measures were conducted by removing samples having more than $1 \%$ of $\mathrm{CpG}$ sites with a detection $p$ value $>0.05$, removing $\mathrm{CpG}$ sites having more than $5 \%$ of samples with a detection $p$ value $>0.01$, and individual CpG sites with detection $p$ value $>0.01$ set as missing. After these QC filters, 484,366 CpG sites were eligible for analysis. We normalized the $\beta$ scores using the Subset-quantile Within Array Normalization (SWAN) method in minifi package to correct for differences between batches and the type I and type II assay designs within a single $450 \mathrm{~K}$ array [28]. Cell count proportions (CD8 T lymphocytes, CD4 T lymphocytes, natural killer cells, B cells, and monocytes) were created using the algorithm developed by Houseman, which predicts underlying cellular composition of each sample from DNA methylation patterns [29].

GOLDN. CD4+ T-cells were isolated from frozen buffy coat samples stored from whole blood peripheral blood collected at the baseline visit (prior to intervention). DNA was extracted using DNeasy kits (Qiagen, Venlo, Netherlands). 500ng of each DNA sample was treated with sodium bisulfite (Zymo Research, Irvine, CA). Normalization was performed on random subsets of 10,000 CpGs per run, with each array of 12 samples used as a "batch." Probes from the Infinium I and II chemistries were separately normalized and $\beta$ scores for Infinium II probes were then adjusted using the equation derived from fitting a second order polynomial to the observed methylation values across all pairs of probes located $<50 \mathrm{bp}$ apart (within-chemistry correlations $>0.99$ ), where one probe was Infinium I and one was Infinium II. The filtered $\beta$ scores were normalized using the ComBat R-package.

CgG candidate selection. The following $6 \mathrm{CpGs}$ were used to construct our MRS: cg00574958 within CPT1A, cg02650017 within PHOSPHO1, cg06500161 within ABCG1, cg11024682 within SREBF1, cg18181703 within SOCS3, and cg19693031 within TXNIP. To select the CpGs for the score, first we started with results from GOLDN (European Ancestry) and HyperGEN (African Ancestry) EWAS, which found replicated association of CPT1A and 
$A B C G 1$ with MetS, respectively. In those studies, no other genes were statistically significant in the discovery cohort and replicated externally. However, prior work in GOLDN and HyperGEN showed robust associations between cg00574958 (CPT1A) and lipids/BMI and between cg06500161 (ABCG1) and fasting glucose/insulin. To expand our score beyond GOLDN and HyperGEN findings, we included the CpG sites in PHOSPHO1, SREBF1, TXNIP and SOCS2 which - together with $A B C G 1$-comprised the type 2 diabetes methylation risk score published by Chambers, et al [10]. Those additional CpGs were selected due to their association with multiple MetS component traits across at least two race groups in multiple cohorts. Helping to further validate our gene selection a more recent EWAS of MetS reported replicated association for three of our 6 CpGs sites in TXNIP, ABCG1, and SREBF1 [30]. Additional references for these $\mathrm{CpGs}$ and their biological relevance are included in Table 1.

Methylation risk score model building. A logistic mixed model was used to test the association between methylation at each candidate CpG site and MetS in HyperGEN. We adjusted for age, sex, study site, and estimated blood cell counts as fixed effects, and family structure as a random effect. Parallel models were implemented in GOLDN except methylation principal components replaced the estimated blood cell counts to adjust for cell type impurity (GOLDN was of a single cell type). To calculate the MRS, Z-values from the candidate CpG HyperGEN models described above (shown in Table 2) were utilized as weights and multiplied by the $\mathrm{CpG}$-values and the product was summed to generate a risk score for each sample $\left(\left(\mathrm{Z}_{1}{ }^{*} \mathrm{cpg}_{1}\right.\right.$ beta score $)+\left(\mathrm{Z}_{2}{ }^{*} \mathrm{cpg}_{2}\right.$ beta score $)+\ldots\left(\mathrm{Z}^{*} \mathrm{cpg}_{6}\right.$ beta score $\left.)\right)$. The mean and standard deviation of the score in HyperGEN was calculated. Each participants MRS was then standardized by subtracting the mean and dividing by the standard deviation. We used a parallel approach to calculate the standardized MRS in GOLDN by using GOLDN CpG values weighted by the HyperGEN Z-values.

Methylation risk score model performance testing. We compared both HyperGEN and GOLDN characteristics between individuals with (MetS+) and without (MetS-) metabolic syndrome. Significance of these characteristics were calculated using a simple $t$ test for continuous traits and a chi-square test for binary traits. We then tested the association between the

Table 1. CPG selection literature review.

\begin{tabular}{|c|c|c|c|c|}
\hline Gene & Trait(s) & Function & Race/Ethnicity groups & $\begin{array}{l}\text { Direction of } \\
\text { Association (MetS } \\
\text { and/or Diabetes) }\end{array}$ \\
\hline $\begin{array}{l}\text { ATP Binding Cassette sub- } \\
\text { family G member } 1 \\
\text { (ABCG1) }\end{array}$ & $\begin{array}{l}\text { Lipids }[10,12,16,30,47,48] \text {, } \\
\text { diabetes-related }[10-12] \text {, adiposity } \\
{[5,30] \text {, incident CHD }[49]}\end{array}$ & $\begin{array}{l}\text { Macrophage, cholesterol, and } \\
\text { phospholipid transport }\end{array}$ & $\begin{array}{l}\text { Europeans [10-12, 47-49], } \\
\text { African Americans [5], Asians } \\
{[10]}\end{array}$ & $+(23 / 12)$ \\
\hline $\begin{array}{l}\text { Carnitine Palmatoyl } \\
\text { Transferase 1A (CPT1A) }\end{array}$ & $\begin{array}{l}\text { Lipids }[16,47,48,50], \text { Blood } \\
\text { pressure }[14], \text { adiposity }[5,51], \\
\text { metabolic syndrome }[52], \\
\text { adiponectin [53] }\end{array}$ & Fatty acid oxidation & $\begin{array}{l}\text { Europeans [14, 47, 48, 50-52, } \\
\text { 54], African Americans [5, 14, } \\
\text { 53], Hispanic/Latino [14] }\end{array}$ & $-(36)$ \\
\hline $\begin{array}{l}\text { Phosphatase, orphan } 1 \\
\text { (PHOSPHO1) }\end{array}$ & $\begin{array}{l}\text { Lipids }[10,12,48] \text {, diabetes-related } \\
\text { [12], adiposity [12] }\end{array}$ & $\begin{array}{l}\text { Glycerophospholipid biosynthesis } \\
\text { and metabolism }\end{array}$ & $\begin{array}{l}\text { Europeans }[10,12,48], \text { Asians } \\
{[10]}\end{array}$ & $-(23)$ \\
\hline $\begin{array}{l}\text { Suppressor of cytokine } \\
\text { signaling } 3 \text { (SOCS3) }\end{array}$ & $\begin{array}{l}\text { Lipids }[12], \text { diabetes-related, }[10], \\
\text { adiposity }[12,55] \text {, metabolic } \\
\text { syndrome }[56]\end{array}$ & $\begin{array}{l}\text { Regulates cytokine or hormone } \\
\text { signaling, inhibits STAT3 activation }\end{array}$ & $\begin{array}{l}\text { Europeans }[10,55,56], \text { Asians } \\
{[10]}\end{array}$ & $-(23)$ \\
\hline $\begin{array}{l}\text { Sterol regulatory element } \\
\text { binding transcription factor } \\
1 \text { (SREBF-1) }\end{array}$ & $\begin{array}{l}\text { Lipids, }[16,47,48], \text { diabetes-related, } \\
{[10,30] \text {, adiposity }[57]}\end{array}$ & Lipid metabolism and homeostasis & $\begin{array}{l}\text { Europeans }[10,12,47,48,57] \text {, } \\
\text { Asians [10] }\end{array}$ & $+(23)$ \\
\hline $\begin{array}{l}\text { Thioredoxin-interacting } \\
\text { protein (TXNIP) }\end{array}$ & Lipids [48], diabetes-related, $[10,30]$ & $\begin{array}{l}\text { Required for the maturation of } \\
\text { natural killer cells, suppresses tumor } \\
\text { growth }\end{array}$ & $\begin{array}{l}\text { Europeans }[10,12,48], \text { Asians } \\
{[10]}\end{array}$ & $-(23)$ \\
\hline
\end{tabular}

https://doi.org/10.1371/journal.pone.0259836.t001 
standardized MRS and MetS (outcome) using a logistic mixed model in HyperGEN adjusting for age, sex, study site, 4 ancestry principal components, estimated blood cell counts as fixed effects, and family id as a random effect. We conducted a 100,000-permutation test to evaluate statistical significance of the relationship between the MRS and MetS in HyperGEN. In GOLDN we used a logistic mixed model to test the association between the GOLDN standardized MRS and MetS adjusting for age, sex, study site, and methylation PCs as fixed effects, and family id as a random effect. Secondary analysis of the score with individual MetS components and by sex were carried out in each study.

\section{Results}

\section{Study population characteristics}

Demographic characteristics of the HyperGEN $(\mathrm{N}=614)$ and GOLDN $(\mathrm{N}=995)$ populations - with and without MetS-are presented in Table 2. The majority of participants were female in both HyperGEN (66.61\%) and GOLDN (52.26\%), with an overall mean age of 49 and 50 years, respectively. Participants with MetS (MetS+) were older compared to those without (MetS-) (HyperGEN: $52 \pm 10$ years and $46 \pm 11$ years, and GOLDN: $56 \pm 13$ and $44 \pm 16$, respectively) and more likely to be male in GOLDN and female in HyperGEN, respectively. In HyperGEN 56.2\% of participants with MetS had 3 of the 5 (i.e. WC, BP, TG, HDL and FG) possible components $(\mathrm{N}=149)$ and fewer had $4(\mathrm{~N}=77,28.7 \%)$ and $5(\mathrm{~N}=42,15.7 \%)$ components, while in GOLDN, $47.5 \%$ of individuals met 3 out of 5 components $(\mathrm{N}=187), 35.1 \%$ had 4 of $5(\mathrm{~N}=138)$ and $17.3 \%$ had 5 of $5(\mathrm{~N}=68)$ components.

Table 3 shows the 6 candidate CpG association results for MetS in HyperGEN and GOLDN. With the exception of cg02650017 in PHOSPHO1, which was not significant in either study, the direction of association of the $\mathrm{CpG}$ with MetS was consistent between GOLDN and HyperGEN with at least marginal significance. Only cg18181703 in SOC3S was not associated with MetS in GOLDN. Both CPT1A cg00574958 and ABCG1 cg06500161 were strongly associated with MetS in both studies $(\mathrm{P}<0.0001)$. Finally, the direction of association for CPT1A, ABCG1, SOCS3, TXNIP and SREBF1 was consistent with that reported in the literature for MetS and/or diabetes (Table 1).

\section{Risk score discovery and validation}

Fig 1 shows the normal distribution of the standardized MRS in the GOLDN cohort. Results from association analyses of the MRS with MetS after adjustment for covariates in HyperGEN and GOLDN are presented in Table 4. In HyperGEN, the MRS was significantly associated with MetS (permutation test $\mathrm{p}<0.0001$ ), with each standard deviation (SD) increase in the score associated with 2.25 higher odds of having MetS ( $\mathrm{OR}=2.25$; 95\% CI: 1.79-2.86). The MetS and MRS relationship was also significant in GOLDN where similarly, a 1 SD increase in the score was associated with 2.45 higher odds of having MetS (OR $=2.45$; 95\% CI: 2.02-3.00). Results for the individual components show the score was most strongly associated with waist circumference, triglycerides and glucose in each study (Table 4). Results stratified by sex show showed the score was generally consistent by gender though slightly more significant in females. We also tested the interaction between MetS and sex, however that interaction was not significant in either HyperGEN or GOLDN.

\section{Discussion}

Signatures of DNA methylation associated with cardiometabolic diseases have not been widely tested for their utility in generating genomic risk scores. With better replication results across 
Table 2. Baseline characteristics of HyperGEN and GOLDN study participants.

\begin{tabular}{|c|c|c|c|c|c|c|}
\hline & \multicolumn{3}{|c|}{ HyperGEN N = 614} & \multicolumn{3}{|c|}{ GOLDN N = 995} \\
\hline & \multirow{2}{*}{$\begin{array}{l}\text { MetS - } \\
\mathrm{n}=346\end{array}$} & \multirow{2}{*}{$\begin{array}{l}\text { MetS + } \\
\text { n }=\mathbf{2 6 8}\end{array}$} & \multirow[t]{2}{*}{$\mathbf{P}^{*}$} & \multirow{2}{*}{$\begin{array}{l}\text { MetS - } \\
\mathrm{n}=602\end{array}$} & \multirow{2}{*}{$\begin{array}{c}\text { MetS+ } \\
\mathbf{n}=393\end{array}$} & \multirow[t]{2}{*}{$\mathbf{P}^{*}$} \\
\hline & & & & & & \\
\hline \multicolumn{7}{|l|}{ Sex } \\
\hline Female (\%) & 61.85 & 72.76 & 0.014 & 56.81 & 45.29 & $<0.001$ \\
\hline Age & $45.67 \pm 11.02$ & $51.66 \pm 10.35$ & $<0.0001$ & $44.01 \pm 16.03$ & $56.16 \pm 13.88$ & $<0.0001$ \\
\hline \multicolumn{7}{|l|}{ High WC } \\
\hline $\mathrm{WC}(\mathrm{cm})$ & $96.56 \pm 16.91$ & $112.40 \pm 16.55$ & $<0.0001$ & $89.35 \pm 13.35$ & $107.57 \pm 13.89$ & $<0.0001$ \\
\hline \multicolumn{7}{|l|}{ Elevated BP } \\
\hline SBP (mmHg) & $127.59 \pm 23.72$ & $136.03 \pm 22.83$ & $<0.0001$ & $110.65 \pm 14.17$ & $123.21 \pm 17.54$ & $<0.001$ \\
\hline $\mathrm{DBP}(\mathrm{mmHg})$ & $75.48 \pm 13.25$ & $75.25 \pm 11.84$ & $<0.0001$ & $66.09 \pm 8.46$ & $71.39 \pm 9.78$ & $<0.0001$ \\
\hline \multicolumn{7}{|c|}{ Elevated Triglycerides } \\
\hline & $77.00 \pm 35.82$ & $125.50 \pm 134.61$ & $<0.0001$ & $91.44 \pm 61.22$ & $176.92 \pm 107.2$ & $<0.0001$ \\
\hline \multicolumn{7}{|l|}{ Reduced } \\
\hline \multicolumn{7}{|l|}{ HDL } \\
\hline Cholesterol & $58.75 \pm 15.52$ & $46.93 \pm 12.45$ & $<0.0001$ & $49.54 \pm 13.22$ & $39.22 \pm 11.44$ & $<0.0001$ \\
\hline \multicolumn{7}{|l|}{ Elevated FG } \\
\hline FG & $89.00 \pm 31.22$ & $110.00 \pm 69.88$ & $<0.0001$ & $94.0 \pm 10.34$ & $105.0 \pm 18.91$ & $<0.0001$ \\
\hline MetS MRS & $-0.38 \pm 0.95$ & $0.31 \pm 0.94$ & $<0.0001$ & $-0.30 \pm 0.93$ & $0.47 \pm 0.92$ & $<0.0001$ \\
\hline \multicolumn{7}{|c|}{ Metabolic Components** } \\
\hline 0 & 57 & 0 & & 174 & 0 & \\
\hline 1 & 115 & 0 & & 214 & 0 & \\
\hline 2 & 169 & 0 & & 214 & 0 & \\
\hline 3 & 0 & 149 & & 0 & 187 & \\
\hline 4 & 0 & 77 & & 0 & 138 & \\
\hline 5 & 0 & 42 & & 0 & 68 & \\
\hline
\end{tabular}

Abbreviations: MetS = Metabolic Syndrome, WC = Waist Circumference, BP = Blood Pressure, SBP = systolic blood pressure, $\mathrm{DBP}=$ diastolic blood pressure, $\mathrm{HDL}=$ high-density lipoprotein, $\mathrm{FG}=$ Fasting glucose .

Thresholds: (1) Waist circumference ( $\geq 88 \mathrm{~cm}$ for women and $\geq 102 \mathrm{~cm}$ for men), (2) elevated triglycerides ( $\geq 150 \mathrm{mg} / \mathrm{dL}$ ) or on treatment for dyslipidemia (statin and/or fibric acid derivative), (3) reduced high-density lipoprotein (HDL) cholesterol ( $<40 \mathrm{mg} / \mathrm{dL}$ in men and $<50 \mathrm{mg} / \mathrm{dL}$ in women) or on treatment for dyslipidemia (statin and/or fibric acid derivative), (4) elevated blood pressure (systolic $\geq 130$ and/or diastolic $\geq 85 \mathrm{mmHg}$ ) or antihypertensive drug treatment in a patient with a history of hypertension), and (5) elevated fasting glucose ( $\geq 100 \mathrm{mg} / \mathrm{dL}$ ) or drug treatment for elevated glucose.

* Significance determined using chi-square test for categorical, t-test for continuous, or kruskal test for non-parametric continuous variables with $95 \%$ CI.

${ }^{* *}$ Metabolic components are high waist circumference, elevated triglycerides, reduced HDL cholesterol, elevated blood pressure, and elevated fasting glucose.

***There are 5 individuals with NA for 1-2 components making the total 341 rather than 346 for MetS- in HyperGEN.

external groups and even by race these CpGs may prove useful for evaluating disease risk. Here, we introduce a six-CpG methylation risk score estimate for MetS that was consistent in two independent populations (HyperGEN and GOLDN). Overall, the successful performance of this MRS in two different racial populations, provides promise for future exploration of MRSs for complex disease prediction.

A substantial number of studies support the role of DNA methylation in MetS and its components. However, unlike studies of single nucleotide polymorphisms (SNPs) that have extensively considered the utility of GRS and PRS (noting many limitations, especially with respect to race), relatively few publications have included MRS [3,31]. For instance, Hamilton et al, reported a positive association between an epigenetic BMI risk score and higher BMI $\left(\mathrm{R}^{2}=\right.$ 0.1) in the Lothian Birth Cohort [32]. MRS for arterial stiffness measurements have been 
Table 3. Single CPG and MetS association results for GOLDN and HyperGEN.

\begin{tabular}{|c|c|c|c|c|c|c|}
\hline & Genes & CpG site & Estimate & SE & Z-score & P-value \\
\hline \multirow[t]{6}{*}{ HyperGEN* Participants $(\mathrm{N}=614)$} & CPT1A & $\operatorname{cg} 00574958$ & -0.495 & 0.113 & -4.396 & $1.10 \mathrm{E}-05$ \\
\hline & PHOSPHO1 & $\operatorname{cg} 02650017$ & -0.133 & 0.101 & -1.312 & 0.189 \\
\hline & $A B C G 1$ & $\operatorname{cg} 06500161$ & 0.550 & 0.113 & 4.865 & $1.15 \mathrm{E}-06$ \\
\hline & SREBF1 & $\operatorname{cg} 11024682$ & 0.570 & 0.119 & 4.777 & $1.78 \mathrm{E}-06$ \\
\hline & SOCS3 & $\operatorname{cg} 18181703$ & -0.204 & 0.095 & -2.153 & 0.031 \\
\hline & TXNIP & $\operatorname{cg} 19693031$ & -0.402 & 0.102 & -3.939 & $8.18 \mathrm{E}-05$ \\
\hline \multirow[t]{6}{*}{ GOLDN** Participants $(\mathrm{N}=994)$} & CPT1A & $\operatorname{cg} 00574958$ & -0.852 & 0.113 & -7.539 & $4.72 \mathrm{E}-14$ \\
\hline & PHOSPHO1 & $\operatorname{cg} 02650017$ & 0.062 & 0.097 & 0.632 & 0.527 \\
\hline & $A B C G 1$ & $\operatorname{cg} 06500161$ & 0.394 & 0.099 & 3.966 & $7.31 \mathrm{E}-05$ \\
\hline & SREBF1 & $\operatorname{cg} 11024682$ & 0.270 & 0.119 & 2.269 & 0.023 \\
\hline & SOCS3 & $\operatorname{cg} 18181703$ & -0.059 & 0.095 & -0.623 & 0.533 \\
\hline & TXNIP & $\operatorname{cg} 19693031$ & -0.267 & 0.092 & -2.915 & 0.004 \\
\hline
\end{tabular}

*HyperGEN model adjusted for age, sex, study site, 4 ancestry principle components, estimated blood cell counts (CD8T cells, CD4T cells, Natural Killer cells, B-cells, Monocyte cells) as fixed effects, and family id as a random effect.

**GOLDN model adjusted for age, sex, study site, 4 methylation principle components, and family id as a random effect.

https://doi.org/10.1371/journal.pone.0259836.t003

reported using data from the REGICOR and Framingham studies. In that study, two different MRS (based on alternate analytical approaches) were directly associated with arterial distensibility coefficient and inversely with pulse wave velocity [33]. Braun and others constructed a MRS in the Rotterdam study for HDL and triglycerides, finding that HDL-C levels decreased as quartiles of MRS increase, while triglyceride levels increased from the first quartile to the second quartile but remained similar for the third quartile and the fourth quartile of the MRS [34]. In another EWAS for BMI, a MRS constructed from the findings predicted future

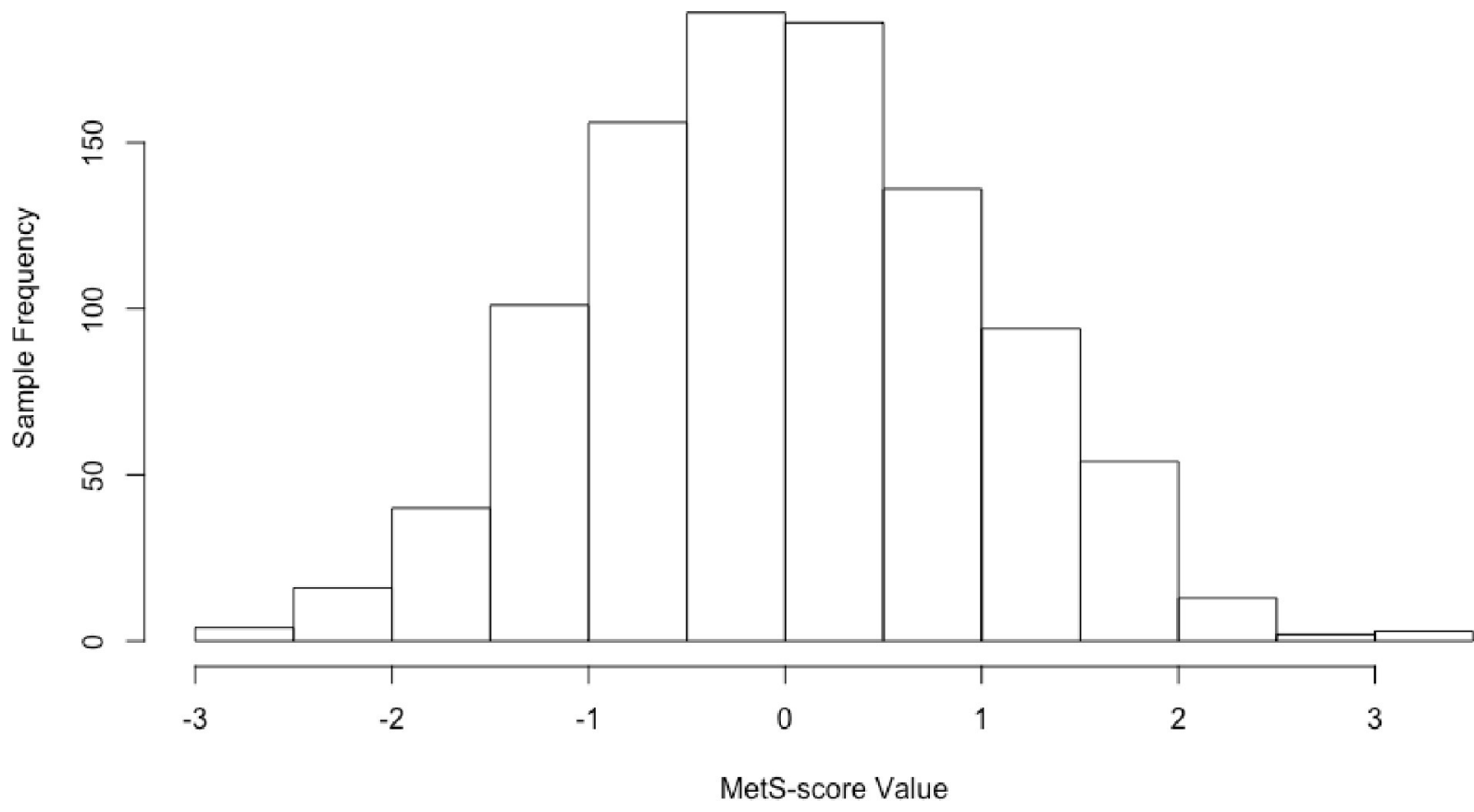

Fig 1. GOLDN MetS-score distribution, $\mathrm{N}=994$. 
Table 4. Cohort-specific association of the Methylation Risk Score (MRS) with MetS and MetS components.

\begin{tabular}{|c|c|c|c|c|}
\hline Outcomes & HyperGEN* & $P$ & GOLDN $^{* *}$ & $\boldsymbol{P}$ \\
\hline MetS & $2.25(1.80-2.86)$ & $6.36 \mathrm{E}-10$ & $2.46(2.03-3.0)$ & $2.0 \mathrm{E}-16$ \\
\hline MetS (M only) & $1.67(1.21-2.33)$ & $2.10 \mathrm{E}-3$ & $2.16(1.65-2.84)$ & $2.49 \mathrm{E}-8$ \\
\hline MetS (F only) & $2.34(1.78-3.02)$ & $3.29 \mathrm{E}-10$ & $2.75(2.06-3.67)$ & $7.53 \mathrm{E}-12$ \\
\hline Elevated BP & $1.36(1.12-1.68)$ & $2.52 \mathrm{E}-3$ & $1.66(1.35-2.04)$ & $1.65 \mathrm{E}-6$ \\
\hline High WC & $1.81(1.46-2.25)$ & $6.16 \mathrm{E}-8$ & $1.86(1.56-2.23)$ & $7.49 \mathrm{E}-12$ \\
\hline Low HDL & $1.24(1.04-1.49)$ & 0.013 & $1.35(1.15-1.59)$ & $2.50 \mathrm{E}-4$ \\
\hline Elevated TG & $2.10(1.61-2.53)$ & $1.54 \mathrm{E}-9$ & $2.42(2.00-2.94)$ & $2.00 \mathrm{E}-16$ \\
\hline Elevated FG & $2.21(1.80-2.73)$ & $5.42 \mathrm{E}-14$ & $1.81(1.50-2.17)$ & $2.14 \mathrm{E}-10$ \\
\hline
\end{tabular}

*HyperGEN model adjusted for age, sex, study site, 4 ancestry principle components, estimated blood cell counts (CD8T cells, CD4T cells, Natural Killer cells, B-cells, Monocyte cells) as fixed effects, and family id as a random effect. ( $\mathrm{N}=205 \mathrm{M}$ ales (M), 409 Females (F))

${ }^{* *}$ GOLDN model adjusted for age, sex, study site, 4 methylation principle components, and family id as a random effect. $(\mathrm{N}=476 \mathrm{Males}(\mathrm{M}), 520 \mathrm{Females}(\mathrm{F}))$ MetS Components: elevated waist circumference/WC ( $\geq 88 \mathrm{~cm}$ for women and $\geq 102 \mathrm{~cm}$ for men), elevated triglycerides/TG ( $\geq 150 \mathrm{mg} / \mathrm{dL}$ ) or on treatment for dyslipidemia (statin and/or fibric acid derivative), low high-density lipoprotein/HDL cholesterol ( $<40 \mathrm{mg} / \mathrm{dL}$ in men and $<50 \mathrm{mg} / \mathrm{dL}$ in women) or on treatment for dyslipidemia (statin and/or fibric acid derivative), elevated blood pressure/BP (systolic $\geq 130$ and/or diastolic $\geq 85 \mathrm{mmHg}$ ) or antihypertensive drug treatment in a patient with a history of hypertension), and elevated fasting glucose/FG ( $\geq 100 \mathrm{mg} / \mathrm{dL})$ or drug treatment for elevated glucose.

development of type 2 diabetes [35]. Finally, in the study of type 2 diabetes ( 2000 Asian Indians and $\sim 1000$ Europeans) the Chambers et al score was associated with developing type 2 diabetes (RR of type 2 diabetes incidence 1.41 per $1 \mathrm{SD}$ change in methylation score; $\left.\mathrm{p}=1.3 \times 10^{-26}\right)[10]$. Along with our study these findings suggest promise in the use of methylation scores for metabolic disease risk prediction.

Generation of genomic risk scores is an evolving field. Some approaches focus on biological candidates and/or statistically significant markers for inclusion, while others include hundreds of thousands or more markers capturing small polygenic effects $[22,36]$. We selected a limited number of CpGs that had strong statistical association with relevant traits and replication in at least two race groups. Each of the CpGs was highly biologically relevant being associated with fatty acid metabolism (CPT1A), reverse cholesterol transport particularly HDL (ABCG1), oxidative stress mediation (TXNIP), phosphatase activity involving glycerophospholipid biosynthesis (PHOSPHO1), inhibition of cytokine signal transduction by binding to tyrosine kinase inhibitors including insulin and leptin receptors (SOCS3), and sterol biosynthesis (SREBF1) (Table 1). Other studies noted above took a similar approach to construct methylation risk scores using statistically significant findings $(20,23)$ or a combination of statistical significance and the literature to select a short list of CpGs (21).

MetS is strongly associated with risk for developing future diabetes and atherosclerotic and nonatherosclerotic cardiovascular disease (CVD). Though beyond the scope of this cross-sectional work, $\mathrm{CpG}$ sites associated with MetS may be the cause or consequence of the condition (or features of the condition). Therefore, a MetS MRS score may capture information about cumulative exposure to risk trait features. Importantly, this information could improve upon existing risk algorithms (constructed from clinical, demographic and lifestyle factors) used to predict future cardiometabolic disease. For instance, in a study set in the Bogalusa Heart Study five well-documented diabetes risk scores (non-genomic) were tested, and all showed significant associations with development of incident diabetes. These five unique risk scores differed slightly by make-up of 5-10 traditional risk factors (e.g. hypertension, smoking, family history of diabetes, age, and waist circumference), but, in general, showed good specificity but poor sensitivity. Because of the low sensitivity, the authors concluded that an opportunity remains 
to develop a new, more sensitive diabetes prediction tools for black and white young adults [37]. The field is similar with respect to CVD risk prediction where an excess of models and different recommendations limit algorithm use [38, 39]. Given the importance of MetS to the cardiometabolic disease landscape, and that MRS may help refine risk metrics in diverse populations for important clinical sequelae, further evaluation of these scores should be considered for disease prediction.

While there are limitations to basing a MRS for MetS from blood-based DNA methylation (due to the proxy nature of blood as a surrogate tissue for organs involved in MetS) [40-42], the utility of blood-based DNA methylation has been proven to be highly feasible and replicable for population studies of glycemic, lipid, and other metabolic traits (Table 1). While we only had access to data derived from blood in GOLDN and HyperGEN, other studies have shown association whole blood and buffy coat are successful proxies for tissues in epigenetic studies [43-45]. Much of the success behind the use of blood/buffy coat as a proxy for tissue can be attributed to the development of new methods to account for things such as cell-type heterogeneity, which we can now accurately account and control for in statistical analyses [46]. To identify whether the MRS was capturing specific components of MetS, we also performed individual association analyses between the individual components of MetS and MRS. Our results suggest that relationship between DNA methylation biomarkers and the development of MetS may be driven by fasting glucose and fasting triglycerides, however, those associations were not significantly stronger than associations observed with other MetS components, suggesting relatively similar contributions from all components of MetS to the MRS in HyperGEN and GOLDN. Differential patterns of sex and MetS were also considered in this study. While both HyperGEN and GOLDN had higher proportions of females compared to males-particularly in HyperGEN-sensitivity analyses showed that the MetS score was fairly consistent across sex, with slightly higher associations noted in females compared to males. However, as noted previously, the interaction analyses between MRS and sex were not statistically significant, suggesting that the MRS is unlikely to have been impacted by sex in this study. The cross-sectional nature of this study, and lack of gold standard definition for MetS are potential limitations that should be considered in future MRS assessments. However, this study strengthened by the availability of CpGs paired metabolic data in two well characterized populations enabling both discovery and validation.

In summary, we developed a MRS for MetS using existing EWAS data from two population studies of different race groups. Addition of the calculated MRS variable to a basic model of

MetS further improved model fit in the study used for score validation. Given the strength of association observed in the current study and the strong body of literature surrounding the CpG loci contributing to the methylation risk score, future studies may further development of this metric for evaluating risk of metabolic syndrome.

\section{Author Contributions}

Conceptualization: Bertha A. Hidalgo, Marguerite Ryan Irvin.

Data curation: Bertha A. Hidalgo, Donna K. Arnett, Marguerite Ryan Irvin.

Formal analysis: Bre Minniefield, Amit Patki, Minoo Bagheri.

Investigation: Bertha A. Hidalgo, Donna K. Arnett, Marguerite Ryan Irvin.

Methodology: Bertha A. Hidalgo, Hemant K. Tiwari, Donna K. Arnett.

Resources: Rikki Tanner, Minoo Bagheri, Hemant K. Tiwari.

Writing - original draft: Bertha A. Hidalgo, Bre Minniefield, Marguerite Ryan Irvin. 
Writing - review \& editing: Hemant K. Tiwari, Donna K. Arnett.

\section{References}

1. Dayan N. and Weili Y., [The application of genetic risk score in genetic studies of complex human diseases]. Yi Chuan, 2015. 37(12): p. 1204-10. https://doi.org/10.16288/j.yczz.15-228 PMID: 26704945

2. Musunuru K. and Kathiresan S., Genetics of Common, Complex Coronary Artery Disease. Cell, 2019. 177(1): p. 132-145. https://doi.org/10.1016/j.cell.2019.02.015 PMID: 30901535

3. AR M., et al., Human Demographic History Impacts Genetic Risk Prediction across Diverse Populations. American journal of human genetics, 2017. 100(4).

4. AR M., et al., Clinical use of current polygenic risk scores may exacerbate health disparities. Nature genetics, 2019. 51(4).

5. Demerath E.W., et al., Epigenome-wide Association Study (EWAS) of BMI, BMI Change, and Waist Circumference in African American Adults Identifies Multiple Replicated Loci. Hum Mol Genet, 2015.

6. Zhang X., et al., Epigenome-wide differential DNA methylation between HIV-infected and uninfected individuals. Epigenetics, 2016. 11(10): p. 750-760. https://doi.org/10.1080/15592294.2016.1221569 PMID: 27672717

7. $\mathrm{AB}$ C., et al., Genome-wide DNA methylation pattern in visceral adipose tissue differentiates insulinresistant from insulin-sensitive obese subjects. Translational research: the journal of laboratory and clinical medicine, 2016. 178.

8. $\quad A B C$., et al., DNA methylation map in circulating leukocytes mirrors subcutaneous adipose tissue methylation pattern: a genome-wide analysis from non-obese and obese patients. Scientific reports, 2017. 7.

9. AG I. and AB C., Role of epigenomic mechanisms in the onset and management of insulin resistance. Reviews in endocrine \& metabolic disorders, 2019. 20(1).

10. Chambers J.C., et al., Epigenome-wide association of DNA methylation markers in peripheral blood from Indian Asians and Europeans with incident type 2 diabetes: a nested case-control study. Lancet Diabetes Endocrinol, 2015. 3(7): p. 526-534. https://doi.org/10.1016/S2213-8587(15)00127-8 PMID: 26095709

11. Hidalgo B., et al., Epigenome-wide association study of fasting measures of glucose, insulin, and HOMA-IR in the Genetics of Lipid Lowering Drugs and Diet Network study. Diabetes, 2014. 63(2): p. 801-7. https://doi.org/10.2337/db13-1100 PMID: 24170695

12. Dayeh T., et al., DNA methylation of loci within ABCG1 and PHOSPHO1 in blood DNA is associated with future type 2 diabetes risk, in Epigenetics. 2016. p. 482-8. https://doi.org/10.1080/15592294.2016. 1178418 PMID: 27148772

13. Irvin M.R., et al., Epigenome-wide association study of fasting blood lipids in the Genetics of Lipid-lowering Drugs and Diet Network study. Circulation, 2014. 130(7): p. 565-72. https://doi.org/10.1161/ CIRCULATIONAHA.114.009158 PMID: 24920721

14. Richard M.A., et al., DNA Methylation Analysis Identifies Loci for Blood Pressure Regulation. Am J Hum Genet, 2017. 101(6): p. 888-902. https://doi.org/10.1016/j.ajhg.2017.09.028 PMID: 29198723

15. Pfeiffer L., et al., DNA methylation of lipid-related genes affects blood lipid levels, in Circ Cardiovasc Genet. 2015, 2015 American Heart Association, Inc.: United States. p. 334-42. https://doi.org/10. 1161/CIRCGENETICS.114.000804 PMID: 25583993

16. KF D., et al., Blood lipids influence DNA methylation in circulating cells. Genome biology, 2016. 17(1).

17. Schlaepfer I.R. and Joshi M., CPT1A-mediated Fat Oxidation, Mechanisms, and Therapeutic Potential. Endocrinology, 2020. 161(2).

18. Shimano H. and Sato R., SREBP-regulated lipid metabolism: convergent physiology-divergent pathophysiology. Nat Rev Endocrinol, 2017. 13(12): p. 710-730. https://doi.org/10.1038/nrendo.2017.91 PMID: 28849786

19. Matsuo M., ATP-binding cassette proteins involved in glucose and lipid homeostasis. Biosci Biotechnol Biochem, 2010. 74(5): p. 899-907. https://doi.org/10.1271/bbb.90921 PMID: 20460728

20. Suchacki K.J., et al., PHOSPHO1 is a skeletal regulator of insulin resistance and obesity. BMC Biol, 2020. 18(1): p. 149. https://doi.org/10.1186/s12915-020-00880-7 PMID: 33092598

21. Boyraz M., et al., Effect of Cytokine Signaling 3 Gene Polymorphisms in Childhood Obesity. J Clin Res Pediatr Endocrinol, 2016. 8(4): p. 452-460. https://doi.org/10.4274/jcrpe.3167 PMID: 27611604

22. Qayyum N., et al., Role of Thioredoxin-Interacting Protein in Diseases and Its Therapeutic Outlook. Int J Mol Sci, 2021. 22(5). https://doi.org/10.3390/ijms22052754 PMID: 33803178 
23. Williams R.R., et al., NHLBI family blood pressure program: methodology and recruitment in the HyperGEN network. Hypertension genetic epidemiology network. Ann Epidemiol, 2000. 10(6): p. 389-400. https://doi.org/10.1016/s1047-2797(00)00063-6 PMID: 10964005

24. Palmieri V., et al., Effect of type 2 diabetes mellitus on left ventricular geometry and systolic function in hypertensive subjects: Hypertension Genetic Epidemiology Network (HyperGEN) study. Circulation, 2001. 103(1): p. 102-7. https://doi.org/10.1161/01.cir.103.1.102 PMID: 11136693

25. Akinyemiju T., et al., Epigenome-wide association study of metabolic syndrome in African-American adults. Clin Epigenetics, 2018. 10: p. 49. https://doi.org/10.1186/s13148-018-0483-2 PMID: 29643945

26. Irvin M.R., et al., Genomics of post-prandial lipidomic phenotypes in the Genetics of Lipid lowering Drugs and Diet Network (GOLDN) study. PLoS One, 2014. 9(6): p. e99509. https://doi.org/10.1371/ journal.pone.0099509 PMID: 24905834

27. KG A., et al., Harmonizing the metabolic syndrome: a joint interim statement of the International Diabetes Federation Task Force on Epidemiology and Prevention; National Heart, Lung, and Blood Institute; American Heart Association; World Heart Federation; International Atherosclerosis Society; and International Association for the Study of Obesity. Circulation, 2009. 120(16). https://doi.org/10.1161/ CIRCULATIONAHA.109.192644 PMID: 19805654

28. Maksimovic J., Gordon L., and Oshlack A., SWAN: Subset-quantile within array normalization for illumina infinium HumanMethylation450 BeadChips. Genome Biol, 2012. 13(6): p. R44. https://doi.org/10. 1186/gb-2012-13-6-r44 PMID: 22703947

29. Houseman E.A., et al., DNA methylation arrays as surrogate measures of cell mixture distribution. BMC Bioinformatics, 2012. 13: p. 86. https://doi.org/10.1186/1471-2105-13-86 PMID: 22568884

30. Nuotio M.-L., et al., An epigenome-wide association study of metabolic syndrome and its components. Scientific Reports, 2020. 10(1): p. 1-12. https://doi.org/10.1038/s41598-019-56847-4 PMID: 31913322

31. AR M., et al., Publisher Correction: Clinical use of current polygenic risk scores may exacerbate health disparities. Nature genetics, 2021.

32. Hamilton O.K.L., et al., An epigenetic score for BMI based on DNA methylation correlates with poor physical health and major disease in the Lothian Birth Cohort. Int J Obes (Lond), 2019. 43(9): p. 17951802. https://doi.org/10.1038/s41366-018-0262-3 PMID: 30842548

33. Fernandez-Sanles A., et al., DNA Methylation and Age-Independent Cardiovascular Risk, an Epigenome-Wide Approach: The REGICOR Study (REgistre Glroni del COR). Arterioscler Thromb Vasc Biol, 2018. 38(3): p. 645-652. https://doi.org/10.1161/ATVBAHA.117.310340 PMID: 29326313

34. Braun K.V.E., et al., Epigenome-wide association study (EWAS) on lipids: the Rotterdam Study. Clin Epigenetics, 2017. 9. https://doi.org/10.1186/s13148-016-0304-4 PMID: 28194238

35. Wahl S., et al., Epigenome-wide association study of body mass index, and the adverse outcomes of adiposity. Nature, 2017. 541(7635): p. 81-86. https://doi.org/10.1038/nature20784 PMID: 28002404

36. Lewis C.M. and Vassos E., Polygenic risk scores: from research tools to clinical instruments. Genome Med, 2020. 12(1): p. 44. https://doi.org/10.1186/s13073-020-00742-5 PMID: 32423490

37. BD P., et al., Utility of existing diabetes risk prediction tools for young black and white adults: Evidence from the Bogalusa Heart Study. Journal of diabetes and its complications, 2017. 31(1).

38. L, P., et al., Equalization of four cardiovascular risk algorithms after systematic recalibration: individualparticipant meta-analysis of 86 prospective studies. European heart journal, 2019. 40(7). https://doi. org/10.1093/eurheartj/ehy653 PMID: 30476079

39. JA D., et al., Prediction models for cardiovascular disease risk in the general population: systematic review. BMJ (Clinical research ed.), 2016. 353.

40. C, K., et al., Critical evaluation of the DNA-methylation markers ABCG1 and SREBF1 for Type 2 diabetes stratification. Epigenomics, 2019. 11(8). https://doi.org/10.2217/epi-2018-0159 PMID: 31169416

41. Cortright $\mathrm{D}$., et al., $\mathrm{C} 5 \mathrm{a}$, but not $\mathrm{C} 3 \mathrm{a}$, increases VEGF secretion in ARPE-19 human retinal pigment epithelial cells. Curr Eye Res, 2009. 34(1): p. 57-61. https://doi.org/10.1080/02713680802546658 PMID: 19172471

42. A, H. and C. D, Methodological challenges in constructing DNA methylation risk scores. Epigenetics, 2020. 15(1-2). https://doi.org/10.1080/15592294.2019.1644879 PMID: 31318318

43. Clark S.L., et al., A whole methylome study of ethanol exposure in brain and blood: an exploration of the utility of peripheral blood as proxy tissue for brain in alcohol methylation studies. Alcohol Clin Exp Res, 2018. https://doi.org/10.1111/acer.13905 PMID: 30320886

44. Ma B., et al., Predicting DNA methylation level across human tissues. Nucleic Acids Res, 2014. 42(6): p. 3515-28. https://doi.org/10.1093/nar/gkt1380 PMID: 24445802 
45. Hannon E., et al., Interindividual methylomic variation across blood, cortex, and cerebellum: implications for epigenetic studies of neurological and neuropsychiatric phenotypes. Epigenetics, 2015. 10 (11): p. 1024-32. https://doi.org/10.1080/15592294.2015.1100786 PMID: 26457534

46. Houseman E.A., et al., DNA Methylation in Whole Blood: Uses and Challenges. Curr Environ Health Rep, 2015. 2(2): p. 145-54. https://doi.org/10.1007/s40572-015-0050-3 PMID: 26231364

47. Lai C.Q., et al., Epigenome-wide association study of triglyceride postprandial responses to a high-fat dietary challenge. J Lipid Res, 2016. 57(12): p. 2200-2207. https://doi.org/10.1194/jlr.M069948 PMID: 27777315

48. Sayols-Baixeras S., et al., Identification and validation of seven new loci showing differential DNA methylation related to serum lipid profile: an epigenome-wide approach. The REGICOR study. Hum Mol Genet, 2016. 25(20): p. 4556-65. https://doi.org/10.1093/hmg/ddw285 PMID: 28173150

49. Hedman A.K., et al., Epigenetic Patterns in Blood Associated With Lipid Traits Predict Incident Coronary Heart Disease Events and Are Enriched for Results From Genome-Wide Association Studies. Circ Cardiovasc Genet, 2017. 10(1). https://doi.org/10.1161/CIRCGENETICS.116.001487 PMID: 28213390

50. Frazier-Wood A.C., et al., Methylation at CPT1A locus is associated with lipoprotein subfraction profiles. J Lipid Res, 2014. 55(7): p. 1324-30. https://doi.org/10.1194/jlr.M048504 PMID: 24711635

51. Aslibekyan S., et al., Epigenome-wide study identifies novel methylation loci associated with body mass index and waist circumference. Obesity (Silver Spring), 2015. 23(7): p. 1493-501. https://doi.org/10. 1002/oby.21111 PMID: 26110892

52. Das M., et al., Association of DNA Methylation at CPT1A Locus with Metabolic Syndrome in the Genetics of Lipid Lowering Drugs and Diet Network (GOLDN) Study. PLoS One, 2016. 11(1). https://doi.org/ 10.1371/journal.pone.0145789 PMID: 26808626

53. Aslibekyan S., et al., CPT1A methylation is associated with plasma adiponectin. Nutr Metab Cardiovasc Dis, 2017. 27(3): p. 225-33. https://doi.org/10.1016/j.numecd.2016.11.004 PMID: 28139377

54. Aslibekyan S., et al., A genome-wide association study of inflammatory biomarker changes in response to fenofibrate treatment in the Genetics of Lipid Lowering Drug and Diet Network. Pharmacogenet Genomics, 2012. 22(3): p. 191-7. https://doi.org/10.1097/FPC.0b013e32834fdd41 PMID: 22228203

55. Xu K., et al., Epigenome-wide association analysis revealed that SOCS3 methylation influences the effect of cumulative stress on obesity. Biol Psychol, 2018. 131: p. 63-71. https://doi.org/10.1016/j. biopsycho.2016.11.001 PMID: 27826092

56. Ali O., et al., Methylation of SOCS3 is inversely associated with metabolic syndrome in an epigenomewide association study of obesity. Epigenetics, 2016. 11(9): p. 699-707. https://doi.org/10.1080/ 15592294.2016.1216284 PMID: 27564309

57. Mendelson M.M., et al., Association of Body Mass Index with DNA Methylation and Gene Expression in Blood Cells and Relations to Cardiometabolic Disease: A Mendelian Randomization Approach. PLoS Med, 2017. 14(1). https://doi.org/10.1371/journal.pmed.1002215 PMID: 28095459 